\title{
Analysis of the Local and Global Forces Acting on the Coil Structure of a Modular Slotless Permanent Magnet Generator
}

\author{
Ants Kallaste (Senior Researcher, Tallinn University of Technology, Tallinn, Estonia), \\ Toomas Vaimann (Senior Researcher, Tallinn University of Technology, Tallinn, Estonia), \\ Anouar Belahcen (Professor, Aalto University, Espoo, Finland), \\ Payam Shams Ghahfarokhi* (Researcher, Tallinn University of Technology, Tallinn, Estonia), \\ Anton Rassõlkin (Researcher, Tallinn University of Technology, Tallinn, Estonia)
}

\begin{abstract}
This paper investigates the local and global forces acting on the coil structure of a low-speed modular permanent magnet generator for wind energy application. Two different configurations of the coil structure are studied. The first one consists of separately replaceable single-coil modules, whereas the second consists of three-phase coil-module assemblies. The purpose of the analysis is to investigate the advantages and disadvantages of each configuration in terms of vibrations and mechanical robustness. The investigations also provide the load for the mechanical analysis needed in the design of the retaining structure of the generator. The results show that there are strong fluctuations in the radial forces acting on the single-coil structure. The three-phase coil-module assembly reduces the fluctuations of the radial forces, but it results in an increase of the cogging torque, which is not suitable for the slotless design. Namely, the advantage of the slotless design is to reduce the cogging torque. The computed forces are then used in a structural mechanical simulation, the results of which are validated through strain measurements. The validation procedure is carried out on a specially built mock-up as accessing the generator on site is not possible.
\end{abstract}

Keywords - Cogging torque, Coil forces, Modular system, Permanent magnet generator, Slotless design.

\section{INTRODUCTION}

The wind energy industry becomes a significant consumer of electrical generators worldwide [1]. This puts tight requirements towards system reliability and maintenance costs. One solution to increase the system reliability of wind turbine is to use directly driven permanent magnet generators [2]. By removing the gearbox from the drivetrain, the system reliability will enhance, and the maintenance costs will decrease [3]. However, it will lead to a low rotational speed of the generator. The low rotational speed results in an increase of the generator diameter, where the MW class machines tend to be very large, expensive and difficult to build, transport and install [4].

One possibility to improve machine maintenance and reliability is to use a modular design. The modularity of the machine will improve fault tolerance and reduce the downtime in case of a failure. In the generator, the stator winding failures account for about 20-30\% of all generator failures [5], [6]. These failures are expensive to fix and take considerable time.
According to [7], [8], generator failures average to about 150 hours of downtime. The use of segmentation would reduce the time and cost of the fault in case of winding replacement, [9]-[12].

However, using the modular topology will also introduce additional air-gaps in the machine flux path. These additional air-gaps can lead to higher machine cogging torque, reduction in the back EMF, change in the winding factor, etc. [13], [14]. In this paper, a modular concept is introduced for the slotless permanent magnet machine. The study is concentrated on the local forces occurring in the module section.

\section{CONSTRUCTION OF THE MACHINE}

In the paper, a slotless PM generator for wind turbines is investigated. A full description of this machine type can be found in [15]. The principal design of the machine is shown in Fig. 1. The machine consists of a surface-mounted permanent magnet rotor and a slotless stator, which consists of concentrated air-gap winding and back iron. The machine parameters are given in Table I.

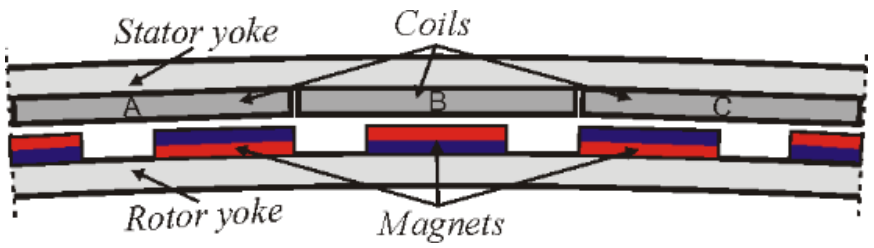

Fig. 1. The principal design of the slotless PM generator presenting one section of it.

In the given design, the number of poles and number of coils is chosen so that for each three coils there are four poles, meaning that the three-coil system is forming one symmetrical three-phase generator system, later referred to as one coil section.

\footnotetext{
* Corresponding author.

E-mail: Payam.Shams@taltech.ee
}

(C)2019 Ants Kallaste, Toomas Vaimann, Anouar Belahcen, Payam Shams Ghahfarokhi, Anton Rassõlkin.

This is an open access article licensed under the Creative Commons Attribution License

(http://creativecommons.org/licenses/by/4.0), in the manner agreed with Sciendo. 
TABLE I

SLOTLESS PM GENERATOR PARAMETERS

\begin{tabular}{|l|c|c|}
\hline Name & Unit & Value \\
\hline Electrical power & $\mathrm{kW}$ & 3000 \\
\hline Rotational speed & $\mathrm{rpm}$ & 13 \\
\hline Torque & $\mathrm{kN} \cdot \mathrm{m}$ & 2090 \\
\hline Air-gap radius & $\mathrm{m}$ & 6.3 \\
\hline Air-gap height & $\mathrm{mm}$ & 10 \\
\hline Magnet dimensions & $\mathrm{mm}$ & $20 \times 100 \times 800$ \\
\hline Coil dimensions & $\mathrm{mm}$ & $20 \times 200 \times 800$ \\
\hline Number of coils per magnets & - & $3 / 4$ \\
\hline
\end{tabular}

\section{FORCES ON THE COILS}

To make a modular machine with replaceable windings, two possible solutions can be considered. In the first, each coil is a separate system (Fig. 2a) and can be replaced. In the second option, three coils form a section, which is detachable (Fig. 2b). Making the coils detachable also means that there will be additional air-gaps in the machine flux path, as illustrated in Fig. 2. These air-gaps cannot be reduced to zero, because of the manufacturing tolerances and the need for easier coil removal. For the given machine, the total gap on the yoke perimeter was chosen to be $0.5 \mathrm{~mm} \times$ number of coils.
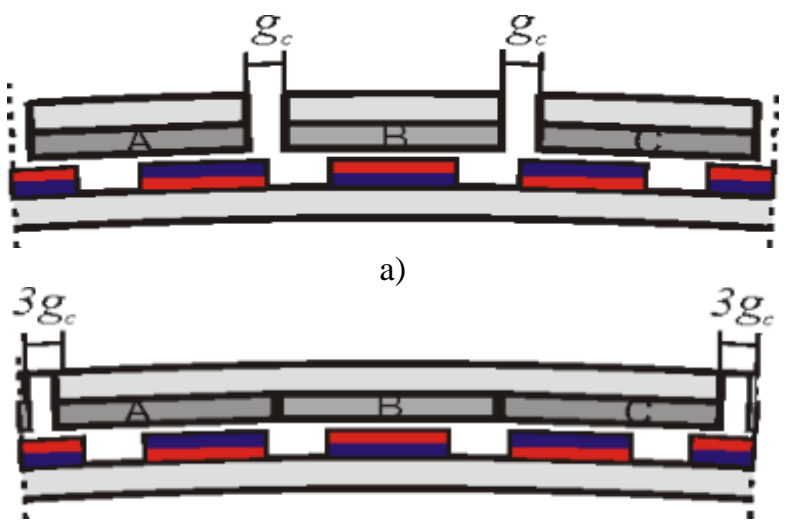

b)

Fig. 2. Modular generator system: a) system where each coil is replaceable; b) system where a coil section is replaceable.

Making additional air-gaps in the machine flux path will also result in additional forces on the coil system. If one starts from the Maxwell stress tensor, it turns out that in the machine, the electromagnetic traction can be divided into two parts. First, the tangential or share stress illustrated in Fig. 3a produces useful machine torque. The produced torque of the machine can be calculated as:

$$
T=\oint_{S} \boldsymbol{r} \times\left(\frac{1}{\mu_{0}} B_{n} B_{t} \boldsymbol{t}\right) d S,
$$

where $r$ is the distance to the integration point on a closed surface around the rotor, $B$ is the magnetic flux density, and $t$ the unit tangential vector to the integration surface $S . n$ and $t$ refer to the normal and tangential components.

Second, the normal component of stress, directed across the air-gap, is such that any facing iron surfaces are attracted towards each other. Without the modularity, the normal traction $f_{n}$ would only be between the stator and the rotor, but adding the air-gaps between the coils, there will be additional traction and the resulting force will act on the coil assemblies, as illustrated in Fig. 3b.

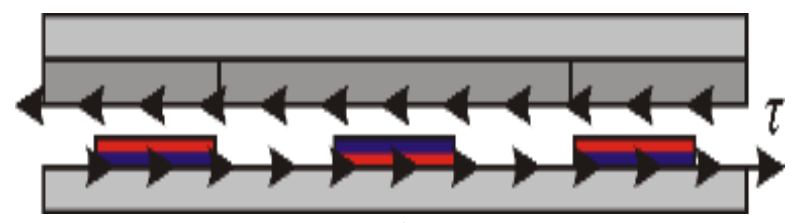

a)

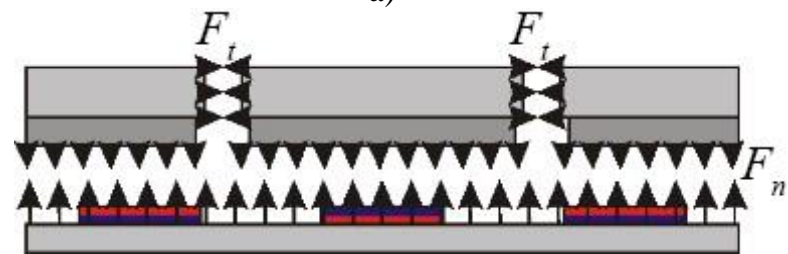

b)

Fig. 3. Structural forces in the machines: a) the shared stress, the useful air-gap force that gives the machine torque; b) normal component of Maxwell stress, the forces trying to close the gaps.

The total force can be calculated as:

$$
\boldsymbol{F}_{n}=\oint_{S} \frac{1}{2 \mu_{0}}\left(B_{n}^{2}-B_{t}^{2}\right) \boldsymbol{n} d S
$$

\section{FEM SIMULATIONS}

To study these additional forces acting on the coil assemblies because of the air-gaps between them, finite element (FE) simulations were carried out. Two case studies were performed for the machine. The forces were simulated for the case where all coils are replaceable and for the case when three coils form a single solid section. For the simulations, the machine model was constructed so that the air-gaps between the coils were equal. To keep the stator radius the same for both cases, the gap over the circumference was chosen also equal.

In the simulation, the $0.5 \mathrm{~mm}$ air-gap between each coil was used and for the coil section case, the air-gap was $1.5 \mathrm{~mm}$ between the coil sections. As the generator radius is very large compared to the pole length, the simulation model was considered as a straight model ignoring the curvature of its parts. In the simulation, the rotor was moved over the length of one pole in steps of $4.6 \mathrm{~mm}$ corresponding to angular motion of 5 electrical deg. The forces acting on the coil assembly were computed from the field solution at every rotor position. To find the forces acting on the coil created by the field from the permanent magnets only, the simulations were carried out at no load. In the simulations, the eddy-current induced by the field was neglected; this is justified because the machine rotational speed is very low and the stator yoke is laminated. The simulations were carried out with the FEMM 4.2 software operated from a MatLab script. The formulation is a quasi-static one in terms of the nodal vector potential, and the permanent magnets are the only source of the field. 


\section{A. Modular Replaceable Coil}

In the case where each coil is replaceable, the computed field distribution in the machine is shown in Fig. 4. Fig. 5a shows the computed radial force acting on the coil assembly as a function of the rotor position. The tangential force is shown in Fig. 5b.

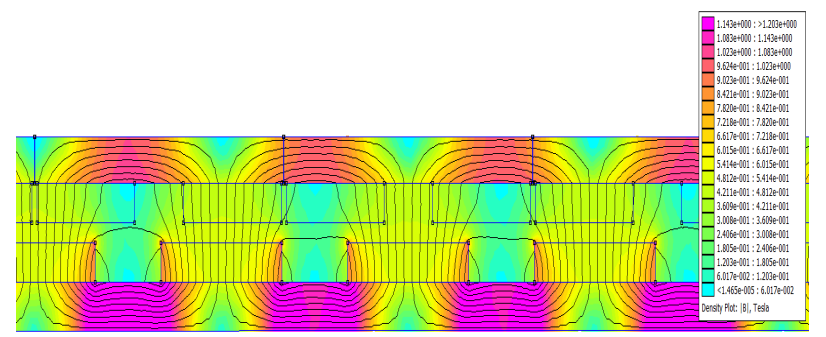

Fig. 4. Filed distribution in the machine with replaceable coils.

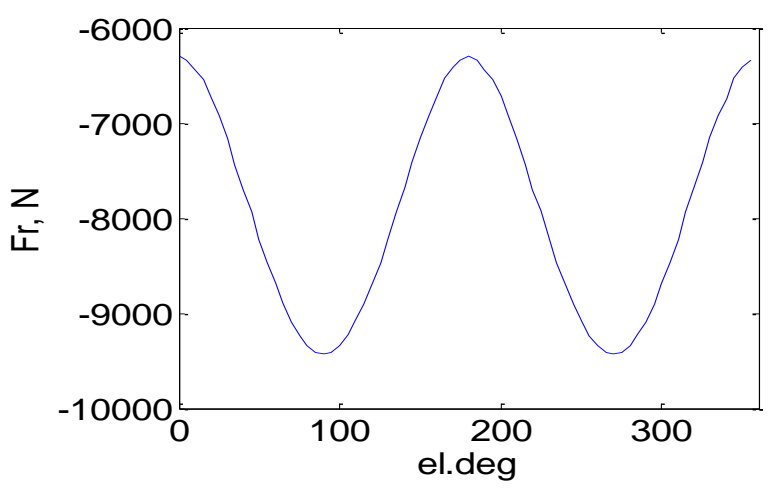

a)

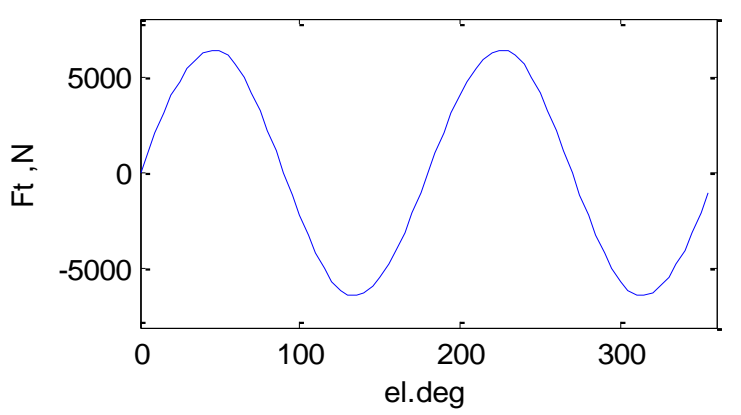

b)

Fig. 5. Forces acting on the coil assembly: a) force in the radial direction; b) force in the tangential direction.

It can be seen from Fig. 5 that in this situation the coil will suffer a strong force fluctuation in the radial direction as well as in the tangential one. The peak-to-peak value of the radial force fluctuation per coil is $3133 \mathrm{~N}$ and that of the tangential force is $12700 \mathrm{~N}$.

The force on the neighbouring coil has the same amplitude but it is shifted by 120 degrees. It is worth noting that summing up all coil forces, the total force on the stator is null as long as the air-gaps are equal. This means that these forces can be seen only locally and not when the whole machine is considered. They do not affect the machine's electromechanical performance, but they have a strong influence on the machine's mechanical structure and its vibrations. The structure holding the coil in the generator has to be stiff and robust to maintain small air-gap clearances. This additional force acting on the coils will be seen as a high fluctuating mechanical stress on the coil support structure, which causes fatigue problems and acoustic noise.

\section{B. Modular Replaceable Coil Section}

One possible solution to avoid these additional forces is to use three-coil sections without any air-gaps between the three coils. In this situation, there will be an air-gap after each section. The computed flux density distribution in the machine for this case is shown in Fig. 6. Fig. 7a shows the computed radial force acting on the coil section and Fig. $7 \mathrm{~b}$ shows the tangential force.

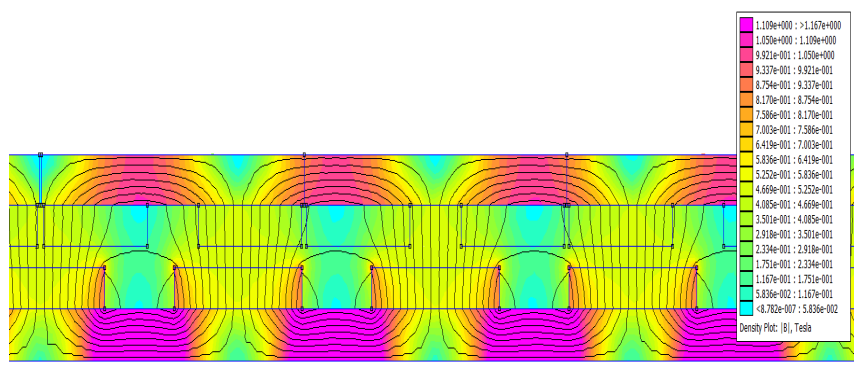

Fig. 6. Field distribution in the machine with replaceable coil section.

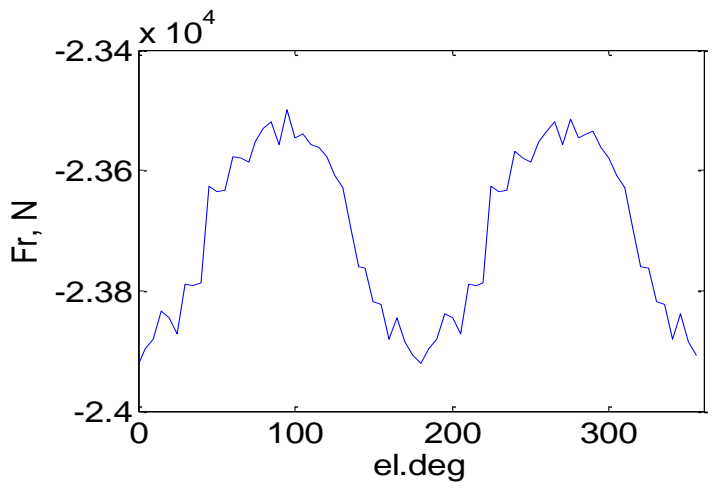

a)

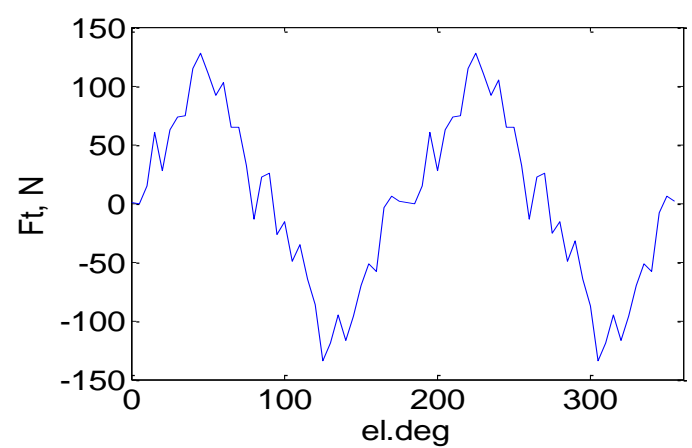

b)

Fig. 7. Forces acting on the coil section: a) force in the radial direction; b) force in the tangential direction.

As Fig. 7 shows, there is still some fluctuation in the coil section forces, but it is drastically reduced compared to the single coil modular system. The peak-to-peak radial force per coil section is now only $400 \mathrm{~N}$ and the tangential one is $260 \mathrm{~N}$. However, it has to be noted that while the forces are reduced drastically, this solution will lead to yet another problem. In the 
single coil modular system, the fluctuations in the coils tangential forces sum up to zero and thus do not produce remarkable torque fluctuation. Nevertheless, when using the modular coil section solution, the fluctuating forces will not sum up to zero as all coil sections are in phase with each other. These forces will add to each other and net fluctuating torque will be generated. Overall, this will result in a strong cogging torque in the machine that can be calculated as:

$$
T_{\text {cog }}=r_{g} \sum_{i=1}^{N_{c} / n_{s}} F_{t} \cos \left(2 \pi i \frac{p}{N_{c} / n_{s}}\right),
$$

where $T_{\operatorname{cog}}$ is the cogging torque, $r_{g}$ is the air-gap radius, $N_{c}$ is the number of coils, $n_{s}$ is the number of coils in a section, $F_{t}$ is the tangential force produced by the magnets and $p$ is the number of pole pairs.

The total cogging torque amplitude was found to be around $100 \mathrm{kN} \cdot \mathrm{m}$, which is about $5 \%$ of the machine nominal torque. One of advantages of the slotless machine over conventional machines is that there is no cogging torque. Using the coil section solution in this machine will result in relatively high cogging torque and is not a preferable solution.

\section{TEST SETUP AND MEASUREMENTS}

To study the forces acting on the coil, an experimental mockup test setup was built. The mock-up consisted of stationary magnets and single coils placed on top of the magnets and separated from them by an air gap. The force on any coil was achieved by loading the coil with a given alternating current. The current was low enough so that the armature reaction field could be neglected.

Based on the mock-up configuration, FE calculations were carried out with the applied current in the coil. To validate the computation of the forces acting on the real structure, a FEM based strain calculation was conducted with the forces computed from the electromagnetic field-based FEM simulations.

Loading of the coil unit is illustrated in Fig. 8, where the forces are applied on the area lying directly under the laminations. For tangential forces, the loads are defined to be in the yoke's center of gravity and in the winding center of gravity. Since the radial forces are applied along the same axis, there is no torque; therefore, the radial forces of the yoke and winding can be defined as one by adding these forces together. All other components are added as point mass.

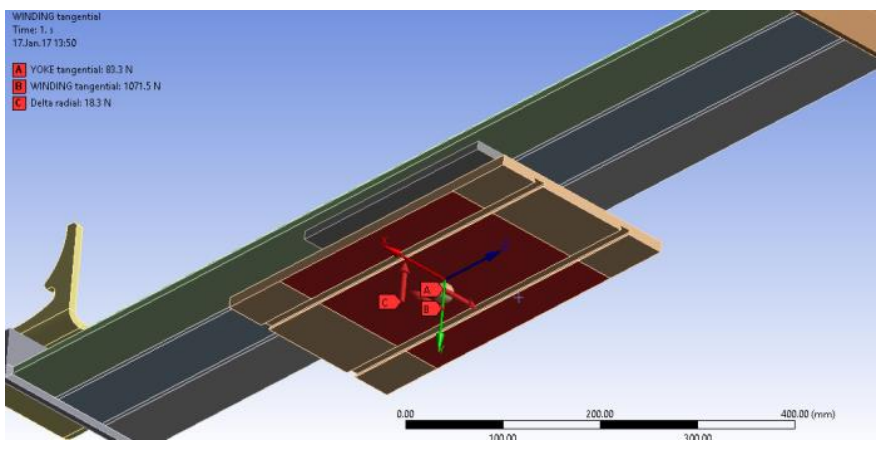

Fig. 8. Forces in the calculated model.
In the strain calculation, two cases were investigated: First, the static magnetic field, where the force is generated by the permanent magnet field, and second, the dynamic case, where the forces are generated by the changing current in the coils.

For the static case, the result of the calculation is given in Fig. 9 where it can be seen that Strain 1 was $80.3 \mu \mathrm{m} / \mathrm{m}$ and Strain 2 was $34.6 \mu \mathrm{m} / \mathrm{m}$.

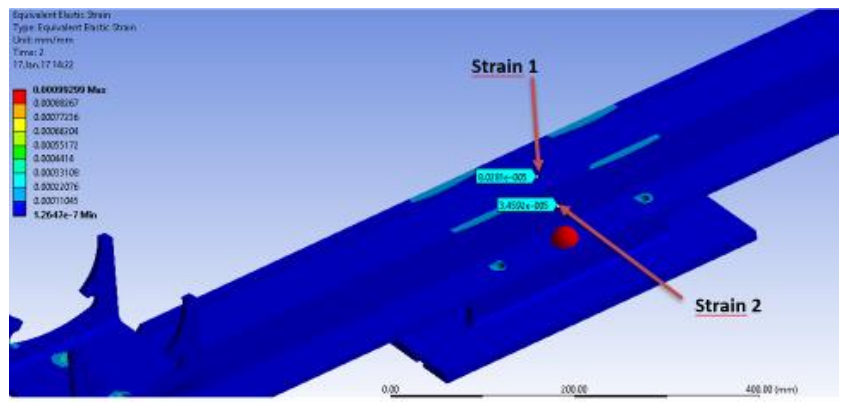

Fig. 9. Calculated strains in the area of sensors in case of the static magnetic field.

In the dynamic strain calculation, only the difference between the maximum and minimum forces was considered. Tangential forces were divided into two parts, where one part of the force is the winding force, generated by the current, and the other part consists of the yoke forces. Both were applied in the component's centre of gravity. In the case of radial force, the electromagnetic influence of the current on the winding was considered. The strain calculation results are given in Fig. 10, where it can be seen that the calculated Strain 1 (radial direction) was $7.1 \mu \mathrm{m} / \mathrm{m}$ and Strain 2 (tangential direction) was $10.9 \mu \mathrm{m} / \mathrm{m}$.

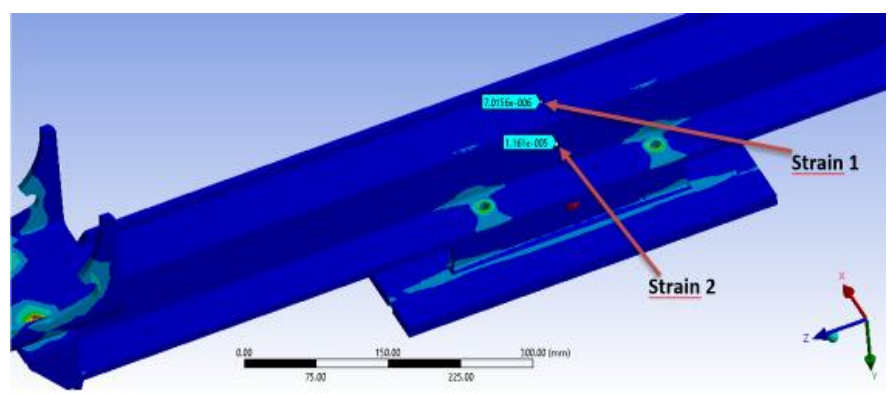

Fig. 10. Calculated strains in the area of sensors in case of the dynamic magnetic field.

In order to get some confirmation about the correlation of the forces/strains that should be there theoretically and that are present in reality in the test setup, a strain sensor was added to the construction. The placement of the sensors on the coil frame is shown in Fig. 11.

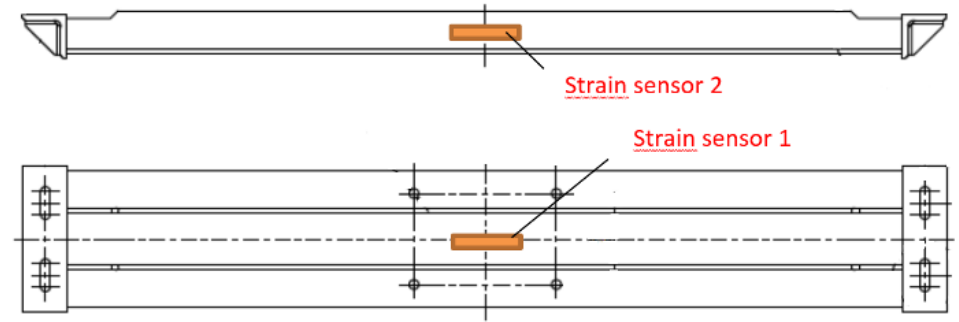

Fig. 11. Placement of the strain sensors on the coil fixing frame. 
The measurement result for the static case is shown in Fig. 12, where it can be seen that the average value for Strain 1 was $105 \mu \mathrm{m} / \mathrm{m}$ and for Strain $2-234.8 \mu \mathrm{m} / \mathrm{m}$.
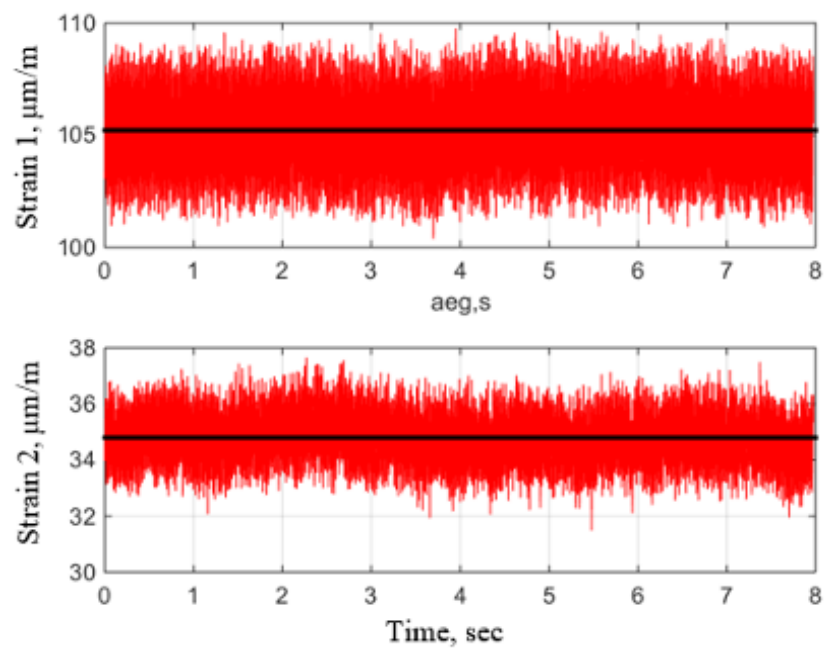

Fig. 12. Strain graph with a static magnetic field.

For the dynamic case, where the current in the coil was equal to the maximum allowed in the coil, the strain measurement results are given in Fig. 13. Table II presents a comparison between the calculated and the measured strains.
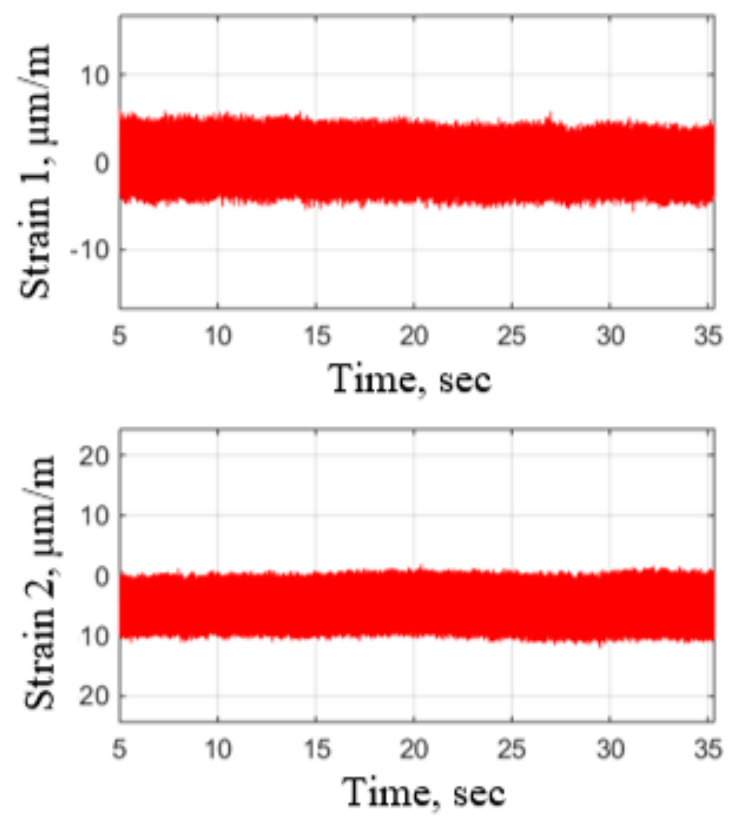

Fig. 13. Strain graph with the dynamic magnetic field.

The difference between the calculated and the measured values can be caused by different reasons. As it can be seen from Fig. 12, even in the stationary load case, the fluctuation of the strain sensor measurements is relatively high. It seems that the used sensor faces some problems if the investigated structure is too rigid and does not deform much, like in the given case. Also, the presented calculations are not absolute, meaning that the strain values in the FEM model change rapidly over small areas. Due to the sensor dimensions and some manufacturing skewness of the adapter, it is difficult to define an exact probing point, the value of which could then be compared to the ones that were measured. Although the measured strain results do not match ideally with the results calculated with FEM, it can be concluded that electromagnetic forces acting on the real structure are similar to the ones that were obtained theoretically.

TABLE II

COMPARISON OF THE CALCULATED AND MEASUREd STRAIN RESUltS

\begin{tabular}{|l|c|c|c|c|}
\hline \multirow{2}{*}{ Test } & Type & $\begin{array}{c}\text { Calculated } \\
\boldsymbol{\mu m} / \mathbf{m}\end{array}$ & $\begin{array}{c}\text { Measured } \\
\boldsymbol{\mu m} / \mathbf{m}\end{array}$ & $\begin{array}{c}\text { Relative } \\
\text { difference }\end{array}$ \\
\hline \multirow{2}{*}{ Static } & Strain 1 & 80.3 & 105.2 & $23.7 \%$ \\
\cline { 2 - 5 } & Strain 2 & 34.6 & 34.8 & $0.6 \%$ \\
\hline \multirow{2}{*}{ Dynamic } & Strain 1 & 7.1 & 4.3 & $-65.1 \%$ \\
\cline { 2 - 5 } & Strain 2 & 11.6 & 12.1 & $4.1 \%$ \\
\hline
\end{tabular}

\section{CONCLUSION}

In the paper, the modular design of a slotless PM generator for wind turbines was introduced. Two different modular solutions were investigated, and FEM simulations were carried out to find the forces acting on the modular system. It was shown that when using a single coil modular system, problems with local forces in the coil will emerge, but these forces do not affect the machine performance. The local force can be reduced using three coil sections as one module, instead of a single coil modular system. This solution results in cogging torque.

\section{REFERENCES}

[1] T. Vaimann, A. Kallaste, N. Korn, S. Laurit, A. Belahcen, "Design of slow-speed slotless SmCo permanent magnet synchronous generator for wind applications," $15^{\text {th }}$ International Scientific Conference on Electric Power Engineering (EPE), IEEE, Brno, Czech Republic, pp. 339-342, May 2014. https://doi.org/10.1109/EPE.2014.6839415

[2] X. P. Yang, X. F. Duan, F. Feng, and L. L. Tian, "Low voltage ridethrough of directly driven wind turbine with permanent magnet synchronous generator," in Asia-Pacific Power and Energy Engineering Conference, APPEEC, 2009, pp. 1-5. https://doi.org/10.1109/APPEEC.2009.4918470

[3] T. Tiirats, O. Pabut, A. Kallaste, H. Herranen, H. Naar, T. Vaimann, "Analysis of Mechanical Vibrations Caused by Eccentricity in a SlowSpeed Slotless Permanent Magnet Generator," Electric Power Quality and Supply Reliability Conference $P Q$ 2014, IEEE, Rakvere, Estonia, June 11-13, 2014, pp. 1-5. https://doi.org/10.1109/PQ.2014.6866819

[4] A. Zavvos, A. S. McDonald, M. Mueller, D. J. Bang, and H. Polinder, "Structural comparison of permanent magnet direct drive generator topologies for 5MW wind turbines," IET International Conference on Power Electronics, Machines and Drives - PEMD, pp. 1-6, 2012. https://doi.org/10.1049/cp.2012.0286

[5] K. Alewine and W. Chen, "A review of electrical winding failures in wind turbine generators," IEEE Electrical Insulation Magazine, vol. 28, no. 4, pp. 8-13, 2012. https://doi.org/10.1109/MEI.2012.6232004

[6] K. Alewine and W. Chen, "A review of electrical winding failures in wind turbine generators," in 2011 Electrical Insulation Conference (EIC), IEEE, 2011, pp. 392-397. https://doi.org/10.1109/EIC.2011.5996185

[7] F. Spinato, P. Tavner, G. van Bussel, and E. Koutoulakos, "Reliability of wind turbine subassemblies," IET Renewable Power Generation, vol. 3, no. 4, p. 387, 2009. https://doi.org/10.1049/iet-rpg.2008.0060

[8] J. Ribrant and L. M. Bertling, "Survey of failures in wind power systems with focus on Swedish wind power plants during 1997-2005," IEEE Trans. Energy Convers., vol. 22, no. 1, pp. 167-173, Mar. 2007. https://doi.org/10.1109/TEC.2006.889614

[9] U. Shipurkar, H. Polinder, J. A. Ferreira, "Modularity in wind turbine generator systems - Opportunities and challenges", 18th European Conference on Power Electronics and Applications (EPE'16 ECCE Europe), Sept. 2016. https://doi.org/10.1109/EPE.2016.7695592 
[10] E. Spooner, Z. Chen, "A Modular Permanent-Magnet Generator for Variable Speed Wind Turbines", IEE Int. Conf. on Electrical Machines and Drives EMD, pp. 453-457, 1995.

[11] E. Spooner, A. Williamson, "Modular permanent-magnet wind-turbine generators", IEEE Industry Applications Conference, pp. 497-502, 1996.

[12] A. Williamson, E. Spooner, L. Thompson, "Large modular PM generators", IEE Colloquium on New Topologies for Permanent Magnet Machines, 1997. https://doi.org/10.1049/ic:19970521

[13] J. Yuan, C.-W. Shi, and J.-X. Shen, "Analysis of cogging torque in surface-mounted permanent magnet machines with segmented stators," $17^{\text {th }}$ International Conference on Electrical Machines and Systems (ICEMS), Hangzhou, China, 22-25 Oct. 2014 https://doi.org/10.1109/ICEMS.2014.7013924

[14] G. J. Li, Z. Q. Zhu, "Analytical Modeling of Modular and Unequal Tooth Width Surface-Mounted Permanent Magnet Machines" IEEE transactions on magnetics, vol. 51, no. 9, September 2015. https://doi.org/10.1109/TMAG.2015.2432735

[15] O. Pabut, M. Eerme, A. Kallaste, T. Vaimann, "Multi-Criteria Design Optimization of Ultra Large Diameter Permanent Magnet Generator" Elektronika ir Elektrotechnika, vol. 21, no. 3, pp. 42-48, 2015. https://doi.org/10.5755/j01.eee.21.3.10278

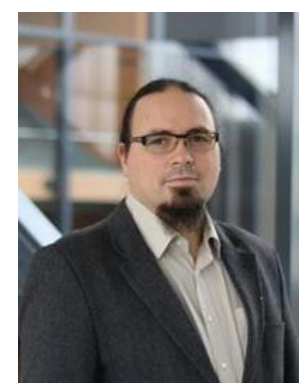

Ants Kallaste received his B. sc., M. sc. and Ph. D. degrees in electrical engineering from Tallinn University of Technology, Estonia, in 2004, 2006 and 2013, respectively. He is currently a senior researcher at Tallinn University of Technology, Department of Electrical Power Engineering and Mechatronics. He is holding the position of Head of Electrical Machines Research Group. He is the member of IEEE and Estonian Society of Moritz Hermann Jacobi.

His main research interest is design of electrical machines.

E-mail: Ants.Kallaste@ taltech.ee

ORCID iD: https://orcid.org/0000-0001-6126-1878

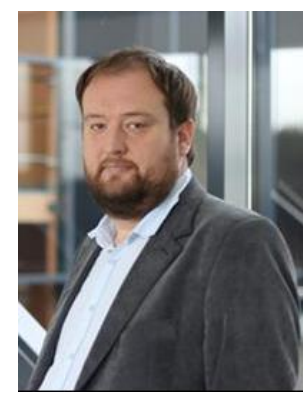

Toomas Vaimann received his B. sc., M. sc. and $\mathrm{Ph} . \mathrm{D}$. degrees in electrical engineering from Tallinn University of Technology, Estonia, in 2007, 2009 and 2014, respectively. He is currently a senior researcher at Tallinn University of Technology, Department of Electrical Power Engineering and Mechatronics. $\mathrm{He}$ has been working in several companies as an electrical engineer. $\mathrm{He}$ is the member of IEEE, Estonian Society of Moritz Hermann Jacobi and Estonian Society for Electrical Power Engineering.

His main research interest is the diagnostics of electrical machines.

E-mail: Toomas.Vaimann@taltech.ee

ORCID iD: https://orcid.org/0000-0003-0481-5066

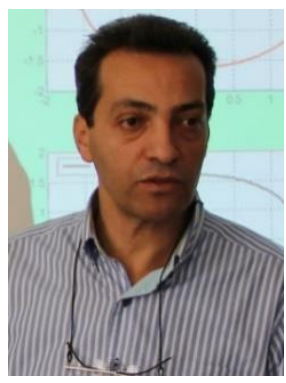

Anouar Belahcen received the B. sc. degree in physics from the University Sidi Mohamed Ben Abdellah, Fes, Morocco, in 1988 and the M. sc. (Tech.) and Doctor (Tech.) degrees from Helsinki University of Technology, Finland, in 1998, and 2004, respectively.

$\mathrm{He}$ is the Professor of Electrical Machines at Tallinn University of Technology, Estonia and the Professor of Energy and Power at Aalto University, Finland.

His research interests are modeling of electrical machines, magnetic materials, coupled magnetic and mechanical problems and magnetostriction.

E-mail: Anouar.Belahcen@taltech.ee

ORCID iD: https://orcid.org/0000-0003-2154-8692

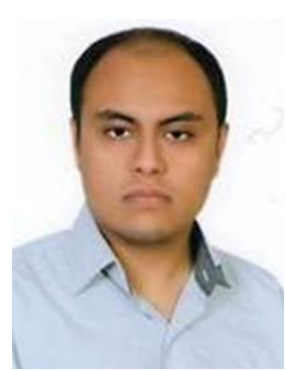

Payam Shams Ghahfarokhi was born in Iran, in 1986. He received the B.Sc. degree in electrical power engineering from IAUN in 2010, the M.Sc. degree in electrical power engineering from Newcastle University in 2011 and the Ph. D. degree from Tallinn University of Technology. He is currently a researcher at Tallinn University of Technology, Department of Electrical Power Engineering and Mechatronics. He has been the IEEE member since 2017. His main fields of interest are design of permanent magnet electrical machine and thermal design of electrical machine.

E-mail: Payam.Shams@taltech.ee

ORCID iD: https://orcid.org/ 0000-0002-6917-5883

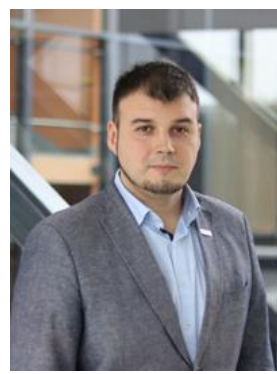

Anton Rassõlkin received a $\mathrm{Ph}$. D. degree in electric drives and power electronics from Tallinn University of Technology in 2014. His main research interests lie in the field of electric drives and their control systems as well as in the fields of electrical machines and electric transportation. He works as a Research Scientist at the Department of Electrical Power Engineering and Mechatronics at Tallinn University of Technology.

Department of Electrical Power Engineering and Mechatronics, Tallinn University of Technology, Ehitajate tee 5, 19086 Tallinn, Estonia.

E-mail: Anton.Rassolkin@ taltech.ee

ORCID iD: https://orcid.org/0000-0001-8035-3970 